nisms isolated from the pregnant patients when compared with women with acute "cystitis," both groups coming from the same geographical area. ${ }^{6}$ It cannot, therefore, be valid to make the comparison in your editorial as support for geographical variation in sulphonamide resistance.-We are, etc.,

Department of Bacteriology,

University College Hospital

R. N. GRÜNEBERG

Department of Bacteriology,

D. S. REEVES

St. Mary's Hospital Medical School,
London $W .2$

1 The Bacteriology Committee of the Association of olory, 1965, 18. 1 . 2 Grüneberg, $\mathbf{R}$. N. ${ }_{\text {Medical foumal, } 1967,3,649 .}^{\text {and }}$ Brumfitt, W., British

3 Williams, J. D., and Smith, E. K., British Medical fournal, 1970, 4. 651.

Mond, N. C., Percival, A., Williams, J. D., and

Brumfitt, W.. Lancet, 1965, 1.514.
Williams, J. D.. Brumfitt, $\mathrm{W}$.

Williams, J. D. B. Brumfitt, W., Leioh, D. A.,
and Percival, A., Lancet, 1965, 1, 831. alliams, J. D., and Leigh, D. A., British foumal
of Clinical Practice, 1966, 20. 177 .

SIR,-I read your leading article on treatment of bacteriuria in pregnancy (12 December, p. 631) with interest but feel some points need clarification. The studies on treatment which we did in north London ${ }^{1}$ did show that a high cure rate of bacteriuria was obtained with a short course of chemotherapy but there are certain features of the population in central areas of industrial cities which make the introduction of a single-dose regimen a necessity for many patients. Many are at work, have large families, and generally lead harassed lives. The addition of a further supply of tablets to their iron and folic acid, antiemetics, and aperients results in some variation in rate at which the tablets disappear. It is sometimes necessary to test the urines of patients for antimicrobials to confirm they are continuing treatment.

The reason why streptomycin was added to sulphonamide given to our patients was because of the relatively common occurrence of sulphonamide resistance in Birmingham. The effect of the streptomycin on these strains was shown in Table III of our paper (12 December, p. 652) and the figures (11 cleared out of 15 compared to 2 out of 11 with sulphonamide alone) are significant ( $p=$ less than 0.05 ).

Finally there are the problems of toxicity and teratogenicity. These cannot be dealt with adequately in a letter but important information on the skin reactions to longacting sulphonamides was obtained during the epidemic of meningitis in Morocco in 1967 , when 110,000 people were treated with sulphadoxine. ${ }^{2}$ Marked differences were found between people treated with single doses and multiple doses. After multiple therapy, cutaneous reactions occurred in $1.4 \%$ of 61,318 patients, with 10 deaths. After single-dose therapy only 5 minor skin reactions were found in 36,673 patients-an incidence of $0.013 \%$ - I am, etc.

Department of Pathology

J. D. Williams Budley Road Hospital,

Williams, J. D., Brumfitt, W., Leigh, D. A., and
Percival, A., Lancet, Percival, A., Lancet, 1965, i, 831 .

ville, J., Annales de Dermatologie, and Male-
1968, 95, 481.

\section{Idiopathic Hypercalciuria and Hyperparathyroidism}

SIR,-We welcome the attempts of Dr. P. Adams and others (5 December, p. 582) to develop provocative tests for the diagnosis of hyperparathyroidism but we are concerned at the implication in their paper that a large proportion of patients now diagnosed as suffering from idiopathic hypercalciuria will prove to have parathyroid adenomata. This is not our view nor is it our intepretation of the results they describe. In particular we question the validity of their normal range for serum calcium.

The demonstration of significant hypercalcaemia requires the careful determination of normal ranges in individual laboratories. ${ }^{12}$

We base our normal range $(8 \cdot 9-10.2 \mathrm{mg} / 100$ $\mathrm{ml}$ ) on data obtained by our colleague Mrs. $\mathrm{M}$. Forbes, and shown in the Figure. Plasma calcium levels were determined in duplicate using emission flame photometry in 73 normal volunteers after a full overnight fast. Reproducibility in determinations on the same specimen was \pm $1 \%$. The values for calcium were corrected for changes in plasma specific gravity. ${ }^{3}$ The subject with the value of $10.7 \mathrm{mg} / 100 \mathrm{ml}$ has been kept under observation. His calcium level has risen slightly and his plasma phosphorus has fallen. We think he has hyperparathyroidism but since he remains well and free of symptoms

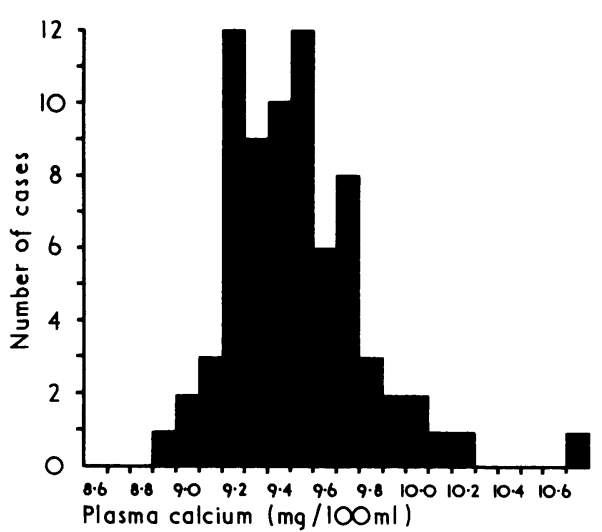

Distribution of plasma calcium in 73 normal volunteers. The values are corrected for changes in plasma specific gravity. ${ }^{3}$

parathyroid surgery has not been undertaken. He clearly belongs to a different population from the other 72 subjects; hence our normal range of $8.9-10.2 \mathrm{mg} / 100 \mathrm{ml}$

We consider that conclusions based on ranges of normal as wide as those described by $\mathrm{Dr}$ Adams and his colleagues $(9 \cdot 0-10.7 \mathrm{mg} / 100 \mathrm{ml}$ ) are open to suspicion. Nor are we surprised that they found parathyroid tumours in some of the 19 patients they reported since most of these had fasting plasma calcium levels above $10.0 \mathrm{mg} / 100 \mathrm{ml}$. We suspect hyperparathyroidism in any patient with renal stones when the fasting plasma calcium is above $10.0 \mathrm{mg} / 100 \mathrm{ml}$ in our laboratories. Among the first 300 patients with parathyroid tumours successfully diagnosed and treated at University College Hospital almost 100 had uncorrected fasting plasma calcium levels below $11.0 \mathrm{mg} / 100$ $\mathrm{ml}$. As a further diagnostic measure in these cases with marginal hypercalcaemia we determine the important plasma ionized calcium level using the method of Roset with modifica tions. While we entirely agree with the final conclusion of Dr. Adams and his colleagues that their 19 patients may represent two different populations, we think these might have been distinguished in large part by more adequate definition of their upper limit of normal for serum calcium and by direct determination for the ionized calcium component. This would greatly lessen the number of indications for provocative tests.

During the last 20 years at University College Hospital and in consultation elsewhere we have seen only six proved cases of hyperparathyroidism with unequivocally normal total plasma calcium levels. In each of these definite, though always minimal, hypercalcaemia was demonstrated later, before surgical exploration was undertaken. During the same time among the many patients referred with renal stones we have seen about 50 patients with idiopathic hypercalciuria who had unnecessary and unrewarding surgical explorations of the neck performed elsewhere. Fortunately the number of these cases has been diminishing in recent years. We regret the implication (unsupported as we see it by adequate evidence) that perhaps half the patients diagnosed as idiopathic hypercalciuria may be suffering from hyperparathyroidism. We fear that this might lead to a new crop of unnecessary operations for hypercalciuria, a mistake we have not yet made ourselves.We are, etc.,

D. R. Davies

C. E. DENT

University College Hospital,
London W.C.1

LYAL WATSON

Dent. C. E., British Medical fournal, 1962, 2, 1419, 1495.

Watson, L., in Modern Trends in Endocrinolooy, ed. H. Gardiner-Hill and F. T. G. Prunty. 3 Dent, C. E., and Watson, L., Lancet. 1968, 2. 662.
1 Rose, G. A., Clinica Chimica Acta 1957, 2, 227.

SIR,-In the interesting paper from Cambridge (5 December, p. 582) hypercalcaemia was provoked in 5 of 19 patients with renal stone by phosphate deprivation. The mechanism by which alteration in dietary inorganic phosphate produces a change in urinary excretion of calcium has caused speculation, and we have recently added to this.

We gave a diet with a very low content of calcium and magnesium to normal adults, patients with hyperparathyroidism, and patients also with renal stones but without hyperparathyroidism, to see if we could distinguish socalled "idiopathic" hypercalciuria from "borderline" hyperparathyroidism. Similar marked renal conservation of both minerals occurred in all the subiects, and the test was a failure. It is also implied that the definition of hypercalciuria is not easy.

We recorded a significant drop in plasma calcium over 10 days on the diet, and as our patients with hyperparathyroidism showed normal renal conservation we agree with MacFadyen and colleagues ${ }^{2}$ that lowered urinary calcium on reducing calcium intake can be explained by reduction in glomerular filtered load without change in tubular reabsorption. Variation in phosphate intake altered urinary calcium and magnesium in the normals and in hyperparathyroidism, and we think that this also can be attributed to change in filtered load on change in plasma calcium. Eisenberg. ${ }^{3}$ has pointed out that decrease in urinary calcium on phosphate loading occurs in normocalcaemic hypoparathyroidism, so that the effect was unlikely to be due to change in tubular reabsorption from alteration in secretion of parathyroid hormone. The Cambridge group have shown lowered phosphate intake may raise the plasma calcium, and earlier Eisenberg ${ }^{4}$ reported low phosphate intake exaggerates hypercalcaemia in hyperparathyroidism. Changes in urinary calcium on phosphate loading or deprivation can now be well explained. 
The most reliable indication of primary hyperparathyroidism is the repeated finding of a raised plasma calcium. Some still take a value of $11.0 \mathrm{mg} / 100 \mathrm{ml}$ as the upper limit of normal in adults, but mostly a lower value is accepted. In Oxford for some time we have considered a fasting reading over $10.5 \mathrm{mg} / 100 \mathrm{ml}$ as suspicious of hypercalcaemia, particularly in patients with renal stone. In Cambridge the upper limit of normal is $10.7 \mathrm{mg} / 100 \mathrm{ml}$ and 7 of the 19 patients with renal stones showed levels of 10.6 and $10.7 \mathrm{mg} / 100 \mathrm{ml}$. It seems possible that the 4 in whom hyperparathyroidism was later proved with plasma calcium levels of more than 10.7 $\mathrm{mg} / 100 \mathrm{ml}$ on provocative testing might have been considered to have shown hypercalcaemia before the testing which effectively raised the blood calcium.

The provocative test by phosphate deprivation and administration of chlorothiazide should prove useful in the diagnosis of "borderline" hyperparathyroidism in the future, and the authors are to be congratulated. The question is raised, however, what should be taken to be the normal range of blood calcium?-I am, etc.,

Milo Keynes

Oxford

1 Kevnes, W. M., Barnes, B. A., and Cope, O.,

MacFadyen, I. J., Nordin, B. E. C.. Smith, D. A., Wayne, D. J., and Ra

Eisenberg, E. in Parathyroid hormone and Thyrocalcitonin (Calcitonin), ed. R. V. Talmage and L. F. Belanger, pp. 465-474.

Eisenberg, E. Fournal of Clinical Endocrinology and Metabolism, 1968, 28,651.

\section{Folic Acid in Epilepsy}

SIR,-Trials of folic acid treatment in patients with epilepsy have been unsatisfactory for two reasons: (a) many trials have been poorly designed or uncontrolled, and (b) the measurement of fit freauency and mental state is, at best, unreliable. Even at a residential centre the recording of fits during the normal daily routine is usually haphazard and unreliable. Dr. Richard Grant and Dr. Olga Stores (12 December, p. 644) say little of the accuracy of their records of patients' fits. If they consider their data and classification of fits reliable it is surprising that they overlooked the significant increase in "tvpe A" fits (grand mal with definite tonic/clonic convulsions) in patients receiving folic acid, compared with those receiving placebo. During the first 26 weeks of treatment 11 patients on folic acid (Table II) showed an increase in "type A" fits, whereas 12 had a decrease or no change. In the placebo group the corresponding figures were 4 and 21 . In a $2 \times 2$ contingency table these totals produce a $\chi^{2}$ value of $4 \cdot 3$ $(p<0 \cdot 05)$. In Table III the calculation of a $t$ value based on the difference in the mean number of attacks is meaningless when the scatter of individual fit scores is so great (0-239 in the control period of the folic acid treated group). Thus, some patients are contributing much greater weight to the mean than others. This might have been avoided by converting each patient's fit score while on treatment to a percentage of the score during the control period.

Recent metabolic studies ${ }^{1}$ suggest that folic acid treatment lowers the serum level of phenytoin by altering the metabolism of this drug. It is unfortunate that patients who had serum phenytoin levels of over $25 \mu \mathrm{g} / \mathrm{ml}$ were excluded from this trial, or stabilized beforehand, for it is these patients who might have shown the greatest change in fit frequency and mental state with folic acid treatment.

A further point which seems not to have been considered in this, or any previously reported trial, is the spontaneous variation of routine serum folate estimations. Thus many patients will be wrongly classified on the results of a single determination, and probablv many patients used in clinical trials of folic acid have not been truly folate depleted. Our recent experience at this hospital is that most epileptic patients with a low serum folate level have a low red cell folate level in addition, suggesting a state of true deficiency. The red cell folate is considered to be a more reliable test for chronic folate depletion, ${ }^{2}$ and it would seem preferable to select patients for a folic acid trial using this criterion.

Nevertheless, this present study, and previous placebo controlled trials of folic acid therapy in epilepsy, ${ }^{3-4}$ should have been sensitive enough to demonstrate the dramatic changes in mental state and fit frequency which have been claimed by Reynolds. ${ }^{5}$ None of these trials has shown such an effect, and the only support for these claims comes from uncontrolled obser vations. However, one cannot lightly dismis well documented case reports, such as that of Chanarin et al. ${ }^{6}$ Future work should be concentrated on identifying folate-depleted patients more carefully and studying a few in depth, with intensive E.E.G. studies sup plementing records of fits.-I am, etc.,

Alan Richens

Division of Clinical Pharmacology

St. Bartholomew's Hospital, Olesen, O. V. and Jensen. O. N., Acta Pharma-
cologica et Toxicologica, 1970, 28. 265.
Millbank, L., Davis, R. E.. Rawlins, M., and
Waters. A. H., fournal of Clinical Pathology,
1970, 23, 54.
Ra'ston, A. I., Snaith, R. P., and Hinley, J. B.,
Lancet. 1970, 1. 867.
Jensen, O. N. and Olesen, O. V., Archives of
Neurology, 1970. 22. 181.
Revnolds, E. H., Iancet. 1967, 1. 1086.
Chanarin. I., I.aidlaw. J. I oughbridge, I.. W.,
and Mollin, D. L., British Medical fournal, 1960,
1, 1099.

\section{Chromosome Aberrations after Exposure to Ultrasound}

SIR,-Chromosomes of human lymphocvtes cultured after exposure to ultrasound (Slade and Coakley) ${ }^{1}$ showed damage similar to that reoorted by $\mathrm{Mr}$. I. J. C. MacIntosh and Dr. D. A. Davey (10 October, p. 92) However, on changing the technique of irradiation the damage was no longer observed.

Lvmphocvtes suspended in TC 199 growth medium were irradiated in heatsealed polythene bags in a plane field at $1 \mathrm{mHz}$ at intensities from $3-45 \mathrm{watt} / \mathrm{cm}^{2}$ for 20 sec. Of 60 cells containing 46 chromosomes examined after culturing for $72 \mathrm{hr}, 26 \mathrm{had}$ aberrations ( 21 chromatid and 16 chromosome breaks or gaps). Damage was no dependent on sonic intensity. The control sample did not grow. In a second experiment in the same intensity range 24 cells had aberrations ( 24 chromatid and 7 chromo- some) in the 116 cells examined. A similarly handled but unsonicated control had five cells with aberrations in the $\mathbf{4 0}$ examined. In contrast, whole blood exposed to ultrasound at similar intensities showed one chromatid break in 30 cells after $72 \mathrm{hr}$, while 136 cells had only one break after $50 \mathrm{hr}$, compared with one in 90 control cells. The disappearance of the effect in whole blood suggests that chromosome damage was not caused by the direct action of ultrasound on the cells.

Subsequently irradiation of whole blood with pulsed ultrasound in an aluminium cylinder with Saran foil (Dow Corning) windows, at $1.0,2.5$ and $3.0 \mathrm{mHz}$ for $1 \mathrm{hr}$, pulse width $60-200 \mu \mathrm{sec}$, duty cycle 0.25 $0 \cdot 1$, peak pulse intensities up to 320 watt $/ \mathrm{cm}^{2}$, showed one abnormality in 270 cells as against one in 60 of the controls after $48 \mathrm{hr}$ growth.

The large number of chromatid aberrations found by $\mathrm{Mr}$. MacIntosh and $\mathrm{Dr}$. Davey and ourselves is remarkable considering that the cells were irradiated at the early $G_{1}$ stage of their cycle. On $x$-irradiation of lymphocytes chomatid breaks arise from damage in the later $S$ and $G_{2}$ stages only. ${ }^{2}$ Normal cells harvested after $72 \mathrm{hr}$ are in the second or third division, since irradiation and chromatid breaks arising from any indirect effect of ultrasound at the moment of irradiation would not still be present after $72 \mathrm{hr}$ unless the first mitosis was considerably delayed by the sonication.

Agents causing chromatid breaks by misreplication during culture include viruses, Mycoplasma, and chemical mutagens. ${ }^{3}$ The persistence of the effect in the cultures treated by $\mathrm{Mr}$. MacIntosh and Dr. Davey suggest that a chemical rather than a biological agent may be operating. The disappearance of the effect in whole blood mav be due to the suppression of ultrasonic cavitation and its accompanying free radicals, but this is unlikely since bubbles, usually associated with cavitation, were not visible under our conditions, and radioactive thvmidine uptake experiments showed no drastic reduction in cell population. Again, the peak intensity used by $\mathrm{Mr}$. MacIntosh and Dr. Davey, is $20 \mathrm{~m}$ watt $/ \mathrm{cm}^{2}$ (personal communication from Smith Kline, the manufacturers), or an acoustic pressure of 0.25 bars, which is lower by a factor of three than the lowest pressure recorded for the onset of cavitation in the $\mathrm{mHz}$ region. ${ }^{4}$

The high incidence of aberrations in our control sample in tissue culture medium in the polythene bag could be due to the release of "toxins" from the containers. The disappearance of the effect in whole blood may be due to the detoxifying effect of whole blood. The release of an enzyme inactivating material from a rubber window of an ultrasonic chamber has been reported by Macleod and Dunn. ${ }^{5}$ Sonication releases ultraviolet absorbing material from dialysis tubing irradiated under the same conditions as the lymphocytes.

The similarity of chromosome damage found by Mr. MacIntosh and Dr. Davey and ourselves suggests that it may be due to the same cause. The high number of chromatid aberrations after $72 \mathrm{hr}$ suggests that a chemical agent, possibly released from the container or due to cavitation, may have been in the culture. The disappear- 